who were unacquainted with those comestibles.

The 1957 edition of Experiments included an informative review of some 320 reagents: from this modest chapter, Mary and Louis Fieser were to develop their monumental series of handbooks entitled Reagents for Organic Synthesis-five volumes comprising more than 4,000 pages of invaluable information and references for research workers.

During the Second World War, Fieser's attention was diverted to investigations on antimalarial drugs of naphthoquinone type. He also played a leading role in the development of incendiary preparations, including napalm. It is clear from his personal account of this work, in the book The Scientific Method that while Fieser relished this challenge to the skill of his research team, he was impatient to resume his own research at the earliest opportunity.

Meanwhile, his enforced travels on war service provided some spare hours in which he began (in collaboration with Mary) the first of a series of sparkling and scholarly textbooks on organic chemistry, in which the excitement of discovery was conveyed in a lively, lucid and gracefully literate style. These works deservedly achieved great international success, both in the original and in translations. The first Japanese edition of the Textbook of Organic Chemistry appeared in 1952 just as peace was formally resumed between the U.S.A. and Japan: its frontispiece portrayed the Fiesers' Siamese cat accompanied by one of Japanese breed, symbolising the authors' hope that their work would promote reconciliation.

In later years, the Fiesers produced two further books for advanced students, Advanced Organic Chemistry (1961) and Topics in Organic Chemistry (1963) together with a Style Guide for Chemists and other works. Fieser also promoted the study of stereochemistry by means of his inexpensive molecular models based on those of Dreiding.

It was typical of Fieser's determination that after undergoing surgery for a lung tumour he became a campaigner on the risks of smoking, in addition to pursuing his customary literary work. The elegance of the latter matched that of his Siamese cats, but in his perseverance Fieser was more appropriately described by his mottoes, which were Omnia possum and Labor omnia vincit.

The human warmth implicit in Fieser's books prompted affection for the author in many readers who had no opportunity of direct contact with him. Friends and disciples known and unknown will salute the memory of a creative and courageous chemist, and offer their condolences to Mary, his wife and scientific partner throughout his career.

C. J. W. Brooks

\section{Sir Frederic Williams}

Professor Sir Frederic Williams, FRS, who died after a year-long illness on 11 August 1977 had held the Edward Stocks Massey Chair of ElectroTechnics at the University of Manchester since 1946; he was famed for his pioneer work on electronic circuitry and digital computers, and was perhaps less well known for his variablespeed induction motors and his new transmission system for a motor-car.

Frederic Calland Williams was born on 26 June 1911. He was educated at Stockport Grammar School, the University of Manchester (B.Sc. and Fairbairn Prize 1932, M.Sc. 1933, D.Sc. 1939) and Magdalen College, Oxford (D.Phil. 1936). He joined the staff of the Electro-Technics Department at Manchester in 1936, but left in 1939 to join the Scientific Civil Service at Bawdsey. During the war he worked on radar at TRE (Telecommunications Research Establishment; now the Royal Radar Establishment). It was at TRE that his inherent ability in circuitry became apparent. Those were the days of valves and he used them in unconventional ways to generate the waveforms required in the rapidly developing field of radar. There were circuits actively using all the electrodes of a pentode; diodes were employed for 'catching'; feedback (both positive and negative) was used. It is believed that Williams introduced the 'virtual earth' idea which so simplifies the analysis of negative feedback amplifiers. At TRE he also made contributions to servomechanisms.

When he became Professor at Manchester, all the war-time experience was incorporated in new courses which he gave to undergraduates (the whole staff attending, too). This experience also enabled him to start new research lines in his department. Most significantly, he brought to Manchester an idea for a digit store for a computer. There were computers in 1946, but they lacked storage. The Williams device stored binary digits as a charge pattern on the screen of a cathode ray tube. The pattern was scanned and read and continuously 'refreshed' by re-writing from the read-out. It was possible to inspect any point of the pattern at random; access time was thus shorter than in acoustic delay lines-a rival system of storage being developed elsewhere.

A complete prototype computing machine incorporating the Williams tube store was built in the laboratory at Manchester and a commercial version was produced by Ferranti Ltd., who installed about 20 computers in various establishments in this country and abroad. Early in the development of the second Manchester machine, Professor Williams' interest in computers waned and he took up other interests. However, he must surely be of that small company of men deserving the title of 'Father of the Computer.'

The new interest was induction machinery. The induction motor is essentially a constant-speed machine, although there are machines with two separate windings either of which can be excited to give a two-speed machine. Williams sought to make an induction motor whose speed could be continuously variable over a range and all of whose windings were used all the time. There was the disc motor derived from the linear induction motor; this was a flea-power machine which demonstrated the practicability of the idea, but it led to the spherical motor in which almost the whole surface of the rotor was in active use. A large motor of this type was made by Metropolitan-Vickers Electrical Company, but the machining of spherical surfaces proved difficult and this may be why no further machines were made.

There followed the 'log-motor' (a machine of amazing ingenuity), the phase-change motor (in which twothirds of the windings were supplied through variable phase changers), several machines with discrete speeds and an induction-excited alternator. $\mathrm{He}$ also produced slow high-torque motors using the direct pull between magnetised surfaces.

Whatever his interest at a particular time, Professor Williams spent practically all his time in the laboratory or the workshop. Administrative work was left as much as possible to others and the time spent at his desk was minimised. He was nearly always to be found, in a cloud of tobacco smoke, supervising the construction of a device or its testing.

He was awarded honorary doctorates from four Universities and was elected to Fellowship of the Royal Society in 1950. He received many medals and other awards. He was made a Knight Bachelor in the Birthday Honours in 1976. In his own University he was held in great respect and affection and he ran his Department with an easy authority; his staff pursued their own interests and under his guidance their individual abilities developed. More than 20 of his protégés are now Professors.

Sir Frederic is survived by Lady Williams, a son, a daughter and four grandsons.

L. S. Piggott 